\title{
RESEARCH
}

\section{Cullin 3 targets the tumor suppressor gene ARMC5 for ubiquitination and degradation}

\author{
Isadora Pontes Cavalcante1, Anna Vaczlavik1,*, Ludivine Drougat1,*, Claudimara Ferini Pacicco Lotfi², \\ Karine Perlemoine1, Christopher Ribes' ${ }^{1}$ Marthe Rizk-Rabin¹, Eric Clauser ${ }^{3}$, \\ Maria Candida Barisson Villares Fragoso ${ }^{4}$, Jérôme Bertherat ${ }^{1,5}$ and Bruno Ragazzon1 \\ 1 Université de Paris, Institut Cochin, INSERM, CNRS, Paris, France \\ 2Department of Anatomy, Institute of Biomedical Sciences, University of São Paulo, São Paulo, Brazil \\ 3Université de Paris, PARCC, INSERM, Paris, France \\ ${ }^{4}$ Adrenal Unit, Hormone and Molecular Genetic Laboratory/LIM42, Hospital of Clinics, School of Medicine, University of São Paulo, São Paulo, Brazil \\ ${ }^{5}$ Department of Endocrinology, APHP, Cochin Hospital, Paris, France
}

Correspondence should be addressed to I P Cavalcante or B Ragazzon: isadoracavalcante@gmail.com or bruno.ragazzon@inserm.fr

*(A Vaczlavik and L Drougat contributed equally to this work)

\begin{abstract}
ARMC5 (Armadillo repeat containing 5 gene) was identified as a new tumor suppressor gene responsible for hereditary adrenocortical tumors and meningiomas. ARMC5 is ubiquitously expressed and encodes a protein which contains a N-terminal Armadillo repeat domain and a C-terminal BTB (Bric-a-Brac, Tramtrack and Broad-complex) domain, both docking platforms for numerous proteins. At present, expression regulation and mechanisms of action of ARMC5 are almost unknown. In this study, we showed that ARMC5 interacts with CUL3 requiring its BTB domain. This interaction leads to ARMC5 ubiquitination and further degradation by the proteasome. ARMC5 alters cell cycle (G1/S phases and cyclin E accumulation) and this effect is blocked by CUL3. Moreover, missense mutants in the BTB domain of ARMC5, identified in patients with multiple adrenocortical tumors, are neither able to interact and be degraded by CUL3/proteasome nor alter cell cycle. These data show a new mechanism of regulation of the ARMC5 protein and open new perspectives in the understanding of its tumor suppressor activity.
\end{abstract}

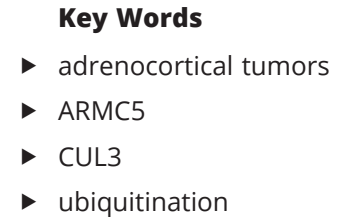

Endocrine-Related Cancer (2020) 27, 221-230

\section{Introduction}

Germline mutations of Armadillo repeat containing 5 gene (ARMC5) were identified in patients diagnosed with multiple bilateral adrenocortical tumors (PBMAH or primary bilateral macronodular adrenal hyperplasia) (Assie et al. 2013, Alencar et al. 2014, Faucz et al. 2014, Gagliardi et al. 2014, Elbelt et al. 2015, Espiard et al. 2015, Bourdeau et al. 2016) conducting to increased production of cortisol. The excess of cortisol (Cushing's syndrome) leads to central obesity, hypertension, diabetes mellitus and osteoporosis. A subset of patients also develop meningiomas (Alencar et al. 2014, Elbelt et al. 2015). These germline mutations are heterozygous and within each tumor a second alteration leads to ARMC5 biallelic inactivation in keeping with the Kudson's two-hit model of tumor suppressor gene. The discovery of ARMC5 alterations established the first direct genetic link to PBMAH, and several cases of familial PBMAH have been described (Alencar et al. 2014, Gagliardi et al. 2014, Elbelt et al. 2015, Bourdeau et al. 2016). In vitro studies in cell lines show that wild type (WT) ARMC5 induces apoptosis (c) 2020 Society for Endocrinology Published by Bioscientifica Ltd. Printed in Great Britain 
and that ARMC5 point mutants lose this ability (Assie et al. 2013, Espiard et al. 2015, Cavalcante et al. 2018). Moreover, in addition to its tumor suppressor gene role, ARMC5 modulates the adrenal steroid production (Assie et al. 2013, Espiard et al. 2015). Armc5 knockout mice suggest a role in embryogenic development and immune system (Berthon et al. 2017b, Hu et al. 2017).

$A R M C 5$, located in the chromosome 16p11.2, is ubiquitously expressed (Berthon et al. 2017a) and encodes a protein of 935 amino acids mostly and uniformly distributed in the cytoplasm (Assie et al. 2013, Espiard et al. 2015). The protein ARMC5 contains a N-terminal Armadillo repeat domain and a C-terminal BTB (Brica-Brac, Tramtrack and Broad-complex) domain, both docking platforms for numerous proteins. To date, the expression regulation and mechanisms of action of ARMC5 are unknown. Two large-scale protein-protein interaction screenings (Bennett et al. 2010, Huttlin et al. 2017), a Yeast Two Hybrid assay (Hu et al. 2017) and co-immunoprecipitation (co-IP) followed by mass spectrometry (MS) analysis (Kouranti I, Abdel Khalek W, Mazurkiewicz S, Pintard L, Jeunemaitre X \& Clauser E, unpublished observations) suggest that ARMC5 interacts with Cullin3 (CUL3).

CUL3 is a protein involved in the ubiquitinproteasome system (UPS), mediating the ubiquitination process and leading to target proteins to the $26 \mathrm{~S}$ proteasome complex (Ciechanover 2017, Dubiel et al. 2018). UPS regulates various important cellular processes, such as cell cycle regulation and cell growth (Ciechanover 2017). Ubiquitination is a process that relies on transferring ubiquitin (Ub) to specific substrates through complexes dependent on the action of an E1 ubiquitin-activating enzyme, an E2 ubiquitin conjugating enzyme and an E3 ligase, which provides the specificity of substrate degradation (Ciechanover 2017). E3 ubiquitin ligases are classified into three main groups: homologous to the E6-AP carboxyl terminus domain (HECT)-type, really interesting new gene (RING)-type and RING-inbetween-RING (RBR)-type E3 ligases (Morreale \& Walden 2016). Cullins are scaffold proteins that organize the largest class of RING E3 ligases known as the cullinRING ligase complexes (CRLs). CRLs typically catalyze the addition of poly-ubiquitin chains to substrates and their subsequent degradation by the proteasome (Ciechanover 2017, Dubiel et al. 2018). CRL3 is composed of the CUL3 protein, the RING protein, RBX1, which binds the E2-enzyme, and a protein with a BTB domain acting as a substrate-specific adaptor (Dubiel et al. 2018).
The substrate adaptor proteins can also be ubiquitinated by the CRL complex which they are a part of, such as Keap1, RhoBTB2 and SPOP (Wilkins et al. 2004, Zhang et al. 2004, Zhou et al. 2015). The balance that regulates the stability of E3 ligases and substrates is important to maintain physiological homeostasis. CRL3s have been involved in various biological processes (cell cycle control, protein trafficking, stress responses and apoptosis) and its alterations have been associated to pathologies (metabolic disorders, muscle atrophy, neurodegeneration and cancer) (Ciechanover 2017, Dubiel et al. 2018).

In this study, we showed that ARMC5 interacts with CUL3 requiring its BTB domain. This interaction leads to the ubiquitination of ARMC5, leading to its degradation by the proteasome. Interestingly, ARMC5 silencing or overexpression alters cell cycle (G1/S phases and cyclin E accumulation) and this effect was blocked by CUL3 (in case of ARMC5 overexpression). Moreover, missense mutants in the BTB domain of ARMC5, identified in patients diagnosed with PBMAH, are neither regulated by the CUL3/proteasome system nor alter cell cycle. These data show a new mechanism of regulation of the ARMC5 protein and open new perspectives in the understanding of the tumor suppressor action of ARMC5 and its role in adrenal tumors development.

\section{Materials and methods}

\section{Cell culture and cell transfection}

The HEK293 and the H295R cell lines authenticated by short tandem repeats analysis were obtained from American Type Culture Collection (ATCC) and cultured as previously described (Ragazzon et al. 2009) for no more than 15 passages and regularly tested for mycoplasma contamination. Human adrenals were obtained after informed consent from two patients undergoing surgery for PBMAH. Adrenal tissue collection was approved by the ethics committee of the Institute of Biomedical Sciences of the University of Sao Paulo. PBMAH cell dissociation and cell culture were performed as previously described (Cavalcante et al. 2018). Cells were transfected with plasmids or/and siRNA with jetPRIME reagent (Polyplus-transfection, Strasbourg, France) according to the manufacturer's instructions. When indicated, cells were treated or not treated with cycloheximide (CHX, Sigma-Aldrich), MG132 (Sigma-Aldrich) and MLN4924 (Calbiochem), Aphidicolin (Sigma-Aldrich) as described in each figure legends. (c) 2020 Society for Endocrinology Published by Bioscientifica Ltd. Printed in Great Britain 


\section{Plasmids and small interfering RNA (siRNA)}

All information and origin concerning the plasmids and siRNA used are listed in Supplementary Table 1 (see section on supplementary materials given at the end of this article). Plasmids were sequenced to confirm the absence of undesirable mutations. More details of plasmids are available on request.

\section{RNA extraction, RT-qPCR and primer sequences}

Total RNA was extracted from the cell lines using Promega RNA extraction kit (Promega), and the expression levels of target genes were determined by means of real-time PCR using a LightCycler Fast Start SYBR Green kit (Roche Diagnostics) according to the manufacturer's instructions. Relative quantification of target cDNA was determined by calculating the difference in cross-threshold $\left(\mathrm{C}_{\mathrm{T}}\right)$ values after normalization to PPIA (CYCLO) signals ( $\triangle \Delta \mathrm{CT}$ method). Primer sequences and conditions for all target genes were described in Supplementary Table 1.

\section{Protein extraction, immunoblotting and immunoprecipitation experiments}

Cell were lysed in lysis buffer $(50 \mathrm{mM}$ Tris/HCl, $150 \mathrm{mM}$ $\mathrm{NaCl}, 5 \mathrm{mM}$ EDTA, $30 \mathrm{mM}$ sodium pyrophosphate, 5 $\mathrm{mM} \mathrm{NaF}, 2 \%$ Triton, $\mathrm{pH} 7.5$ ) supplemented with protease inhibitors and phosphatase inhibitors (Roche), followed by centrifugation at $15,000 \mathrm{~g}$ for $10 \mathrm{~min}$ at $4^{\circ} \mathrm{C}$. Equal amount of proteins were resolved by SDS-PAGE, transferred to nitrocellulose membranes and incubated with primary antibodies overnight at $4^{\circ} \mathrm{C}$. After washing, the membranes were incubated with the secondary antibody used at a dilution of 1:5000 for $1 \mathrm{~h}$ at room temperature. Bound antibodies were revealed using an ECL system (Pierce) and signal detected with a Pxi Camera (Ozyme). For co-immunoprecipitation experiments, cells were lysed in the lysis buffer described above and immunoprecipitations were performed with $800 \mu \mathrm{g}$ of protein extracts with $2 \mu \mathrm{g}$ of mouse anti-FLAG or mouse anti-HA overnight at $4^{\circ} \mathrm{C}$ with gentle agitation, magnetic beads (Protein G Mag Sepharose \#28-9440-08, GE Healthcare) were added for $2 \mathrm{~h}$. After washing, immunoprecipitates were eluted with $2 \times$ SDS loading buffer. For ubiquitination assay, cells were lysed under denaturing conditions (lysis buffer supplemented with $1 \%$ SDS, $1 \mathrm{mMDTT}$ and $1.25 \mathrm{mg} / \mathrm{mL}$-ethylmaleimide (Sigma-Aldrich)) and boiled at $95^{\circ} \mathrm{C}$ for $5 \mathrm{~min}$. For these assays, immunoprecipitations were performed with ANTIFLAG M2 Affinity Gel (Anti-FLAG®M2; Sigma-Aldrich) and immunoprecipitates were eluted with 3X FLAG peptide (F4799, Sigma-Aldrich). All antibodies used in this study are listed in Supplementary Table 1.

\section{Bioluminescence resonance energy transfer (BRET) assays}

The apparent affinity of wild type and the different mutants of ARMC5 for CUL3 were evaluated by BRET. In each experiment, a fixed amount of BRET donor plasmids (WT or mutants ARMC5-luciferase (Luc)) was transfected in HEK293 cells (6-well plates) in association with increasing amounts of the BRET acceptor plasmid CUL3-Yellow Fluorescent Protein (CUL3-YFP plasmid) (10-300 ng). For each transfection point, luciferase, YFP and BRET signals were measured using a Mithras Multimode Microplate reader LB 940 multimode reader (Berthold). BRET results were expressed in milli-BRET units (mBRET), plotted as a function of YFP/Rluc, in which YFP represents the actual amount of expressed BRET acceptor and Rluc, the amount of BRET donor in each sample.

\section{Cell cycle analysis}

For cell cycle experiments, cells were trypsinized, rinsed with PBS and fixed in 70\% ethanol after transfection. Fixed cells were centrifuged, washed with PBS and resuspended in propidium iodide (PI) solution containing $50 \mu \mathrm{g} / \mathrm{mL}$ of PI (Sigma Aldrich) and $100 \mu \mathrm{g} / \mathrm{mL}$ RNAse A (Sigma Aldrich) in PBS. For each experiment, 20,000 events were acquired by flow cytometry using Novocyte Cytometer (Ozyme). Data were analysed using the Novoexpress Software.

\section{Statistical analysis}

Data are presented as mean \pm s.D. No statistical method was used to predetermine sample size. Statistical analyses were performed by student $t$-test, by one-way ANOVA, followed by Tukey's test or by two-way ANOVA. Statistically significant differences are indicated as ${ }^{*} P<0.05,{ }^{* *} P<0.01$ and ${ }^{* * *} P<0.001$.

\section{Results}

\section{CUL3 interacts with ARMC5 through the BTB domain}

We tested the interaction of ARMC5 with CUL3 in human embryonic kidney (HEK293) cell protein extracts. Overexpressed WT ARMC5-FLAG co-immunoprecipitated 
A

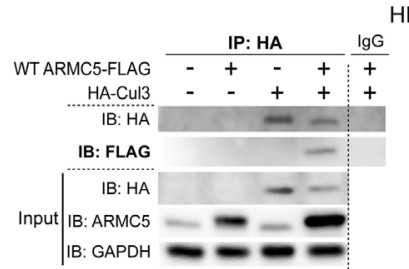

B

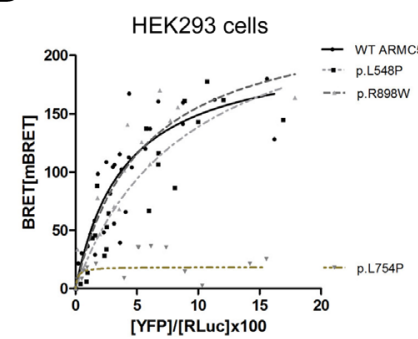

HEK293 cells

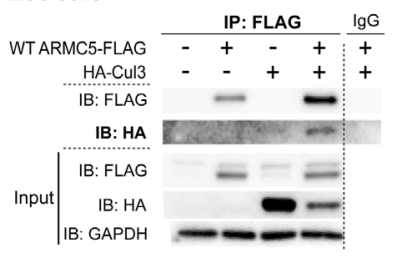

D

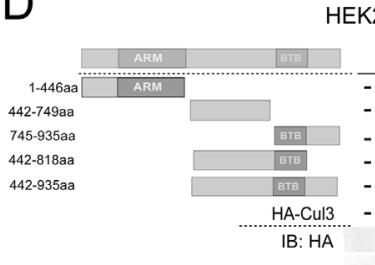

HEK293 cells

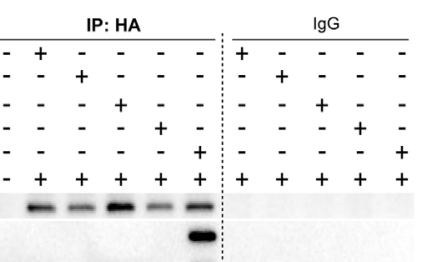

C

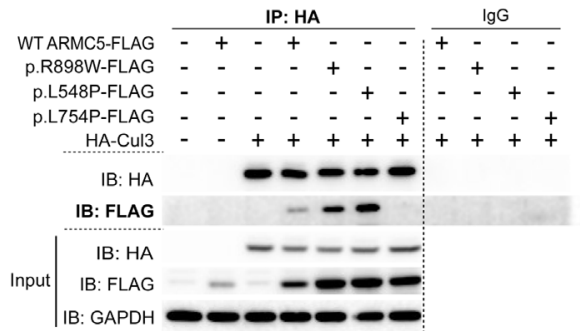

IB: FLAG

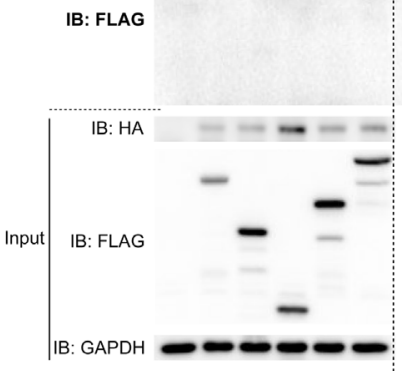

Figure 1

Identification of ARMC5 as a partner of Cullin3. (A) HEK293 cells were transfected with HA-CUL3 and WT ARMC5-FLAG. Cell extracts were immunoprecipitated with HA (left) or FLAG antibodies (right), followed by immunoblotting. (B) Cells were transfected with the indicated constructs, followed by BRET proximity assays. Hyperbolic saturation curves were obtained between CUL3-YFP, WT ARMC5-Luc, R898W ARMC5-Luc and L548P-Luc, but not between CUL3-YFP and L754P ARMC5-Luc. (C) Cells were transfected with HA-CUL3, WT ARMC5-FLAG, R898W ARMC5-FLAG, L548P ARMC5-FLAG and L754P ARMC5-FLAG, followed by immunoprecipitation with HA antibody. The interaction between ARMC5 and CUL3 is disrupted by a mutation in the BTB domain of ARMC5 (L754P). (D) Cell extracts were obtained from cells transfected with the five indicated fragments of the ARMC5 protein-FLAG tagged and HA-CUL3 and immunoprecipitated with HA antibody. Images are representative of at least three independent experiments.

(IP) with HA-CUL3 (Fig. 1A-left panel). Reciprocal co-IP experiments confirmed the interaction between HA-CUL3 with ARMC5-FLAG (Fig. 1A-right panel). This interaction was further analyzed in living cells using a bioluminescence resonance energy transfer (BRET) proximity assay. Specific close proximity $(<10 \mathrm{~nm})$ between ARMC5 and CUL3 was demonstrated by a hyperbolic BRET saturation curve upon the expression of increasing concentrations of the BRET acceptor (CUL3-YFP) in the presence of constant amounts of BRET donor (ARMC5-Luc) (Fig. 1B). Then, we investigated if three ARMC5 missense mutations located in different parts of the protein (p.L548P, p.L754P and p.R898W) and identified in patients diagnosed with PBMAH might alter its interaction with CUL3. ARMC5 p.L754P mutant did not co-immunoprecipitate with HA-CUL3, contrary to ARMC5 WT and mutants p.L548P and p.R898W (Fig. 1C). Similarly, we observed a drastic loss of the BRET signal with BRET donor ARMC5.p.L754PLuc and the acceptor CUL3-YFP, in contrast to ARMC5 WT or to both other ARMC5 mutants (p.L548P and p.R898W) (Fig. 1B). Interestingly, the amino acid 754 is localized in the BTB domain (748-816aa) of ARMC5. Finally, for better characterizing the importance of the BTB domain in this interaction, we used different fragments of ARMC5 protein and observed that only the construction 442-935aa, containing the middle, the BTB and the
C-terminal domains of ARMC5, co-immunoprecipitated with HA-CUL3 (Fig. 1D). However, CUL3 does not interact with shorter protein fragments containing the BTB domain (442-818aa and 745-935aa). Altogether, these complementary approaches demonstrate that ARMC5 and CUL3 form a complex and that the BTB domain of ARMC5 is necessary but not sufficient for this interaction.

\section{ARMC5 is a direct substrate of the CUL3-based ubiquitin ligase complex}

Whereas ARMC5 silencing had no effect on accumulation of CUL3 protein (data not shown), CUL3 silencing leads to increased endogenous ARMC5 protein level without changing ARMC5 mRNA levels in both HEK293 and human adrenocortical (H295R) cell lines (Fig. 2A and B). Moreover, endogenous ARMC5 protein half-life is increased in CUL3deficient cells compared to control cells after inhibition of the de novo protein synthesis (Fig. 2C). To determine whether the mutation in the BTB domain might affect the stability of ARMC5, we compared half-life of overexpressed WT ARMC5-FLAG and mutated L754P ARMC5-FLAG proteins. Half-life of L754P ARMC5-FLAG mutant is higher than WT ARMC5-FLAG (Fig. 2D). Moreover, CUL3 overexpression decreased the half-life of WT ARMC5, while no significant effect was observed on ARMC5 L754P
(C) 2020 Society for Endocrinology Published by Bioscientifica Ltd. Printed in Great Britain 
A
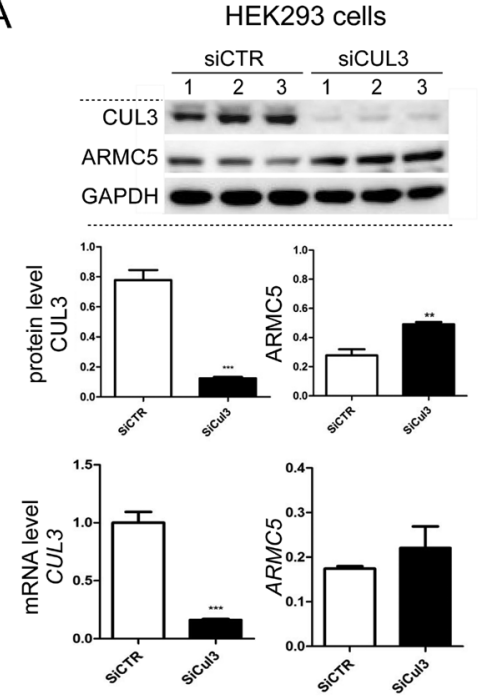

C
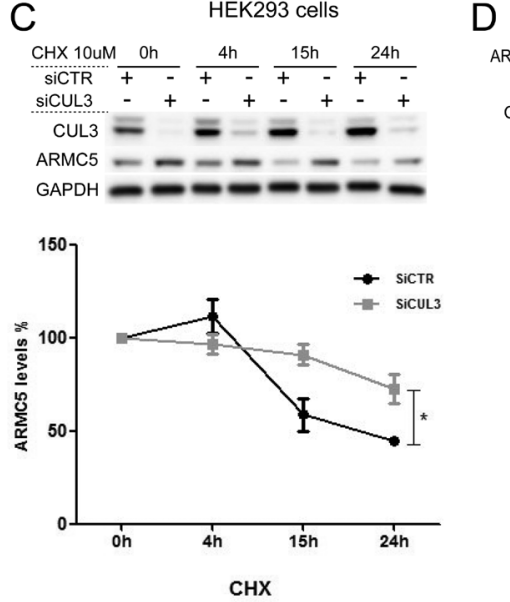

B
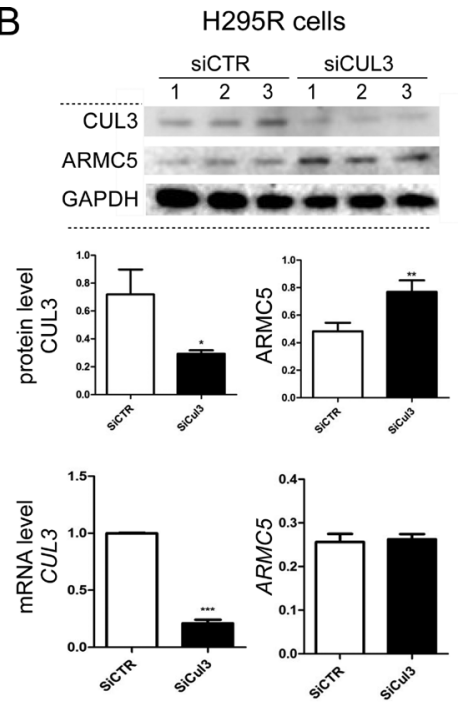

HEK293 cells
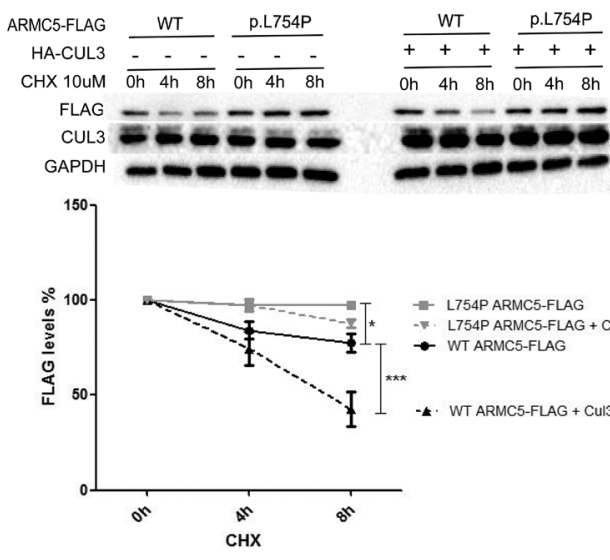

\section{Figure 2}

CUL3 regulates ARMC5 protein stability. CUL3 silencing by three different siRNA increases accumulation of ARMC5 protein (middle panel) without modifying ARMC5 mRNA level (bottom panel) in (A) HEK293 and (B) H295R cells compared to control cells (siCTR). (C) Protein stabilization assays with $10 \mu \mathrm{M}$ cycloheximide (CHX) treatment for 4, 15 and $24 \mathrm{~h}$ were performed, demonstrating that CUL3 knockdown stabilizes ARMC5 protein in HEK293 cells. (D) HEK293 cells were transfected with equal amounts of WT ARMC5-FLAG, L754P ARMC5-FLAG and HA-CUL3 and submitted to $10 \mu \mathrm{M}$ cycloheximide treatment of 4 and $8 \mathrm{~h}$. Co-expression of HA-CUL3 accentuates WT ARMC5 degradation, while no effect is observed in the L754P ARMC5 degradation. Images are representative of at least three independent experiments. To simplify the representation of the results, we only display the most informative comparisons on graph $\mathrm{D}$. All values are provided hereafter: at $4 \mathrm{~h}$ of treatment with $\mathrm{CHX}$, the percentage of protein was $74 \% \pm 12$ (WT + CUL3) vs $97 \pm 1$ (L754P) $(P<0.01) ; 74 \% \pm 12$ (WT + CUL3) vs $97 \% \pm 4(\mathrm{~L} 754 \mathrm{P}+\mathrm{CUL} 3)(P<0.01)$; at $8 \mathrm{~h}$, the percentage of protein was $77 \% \pm 6$ (WT) vs $97 \% \pm 2$ (L754P) $(P<0.05) ; 42 \% \pm 12$ (WT + CUL3) vs $87 \% \pm 3$ $(\mathrm{L} 754 \mathrm{P}+\mathrm{CUL} 3)(P<0.001)$ and $77 \% \pm 6$ (WT) vs $42 \% \pm 12$ (WT + CUL3) $(P<0.001)$. Student's $t$-test was used to analyze experiments $A$ and $B$, and two-way ANOVA followed by Bonferroni post-test was used for experiments $C$ and $D$. mutant (Fig. 2D). These results suggest that CUL3 and potentially the CRL3 complex control the accumulation of ARMC5 protein through a post translational modification.

Inhibition of cullin neddylation (required for CRL activity) with MLN4924 increased endogenous ARMC5 protein level (Fig. 3A). Moreover, in H295R cells and in cell cultures from PBMAH, inhibition of the UPS with MG132 increased accumulation of the endogenous and/or overexpressed ARMC5 WT (Fig. 3B and C-left panel and D-left panel), while no effect was observed in the accumulation of BTB mutated ARMC5 proteins (p.L754P and p.H808P) (Fig. 3C-right panel and D-right panel). These results suggest that ARMC5 half-life and degradation are dependent of its BTB domain and likely regulated by CUL3 and UPS. In order to investigate if ARMC5 is a substrate of the CUL3-based complex, we performed cell-based ubiquitination assays. We observed that CUL3 silencing decreases ubiquitination of overexpressed WT ARMC5 (Fig. 4A). On the other hand, overexpressed WT ARMC5 ubiquitination was increased when CUL3 was co-expressed in both HEK293 and H295R cell lines (Fig. 4B and C). As expected, ubiquitination of overexpressed ARMC5 p.L754P mutant was not increased when CUL3 was co-expressed (Fig. 4B and C). Finally, we performed the same ubiquitination assays using two Ub mutants (K48R and K63R), the most predominant forms of Ub chain linkages in the cell (Ciechanover 2017, Dubiel et al. 2018). Through this approach, we observed that the ubiquitination level of ARMC5 was drastically decreased when Ub-K48R was used, while Ub-K63R did not affect WT ARMC5 ubiquitination (Fig. 4D). This result is consistent with the previously mentioned data (Figs 2 and 3), given that K48-linked Ub chains are the main signal for targeting substrates for degradation by the 26s proteasome (Ciechanover 2017, Dubiel et al. 2018). Taken together, these data provide evidences for a model in which ARMC5 is a direct substrate of a CUL3 ubiquitin ligase complex and is degraded by the UPS. (c) 2020 Society for Endocrinology Published by Bioscientifica Ltd. Printed in Great Britain 

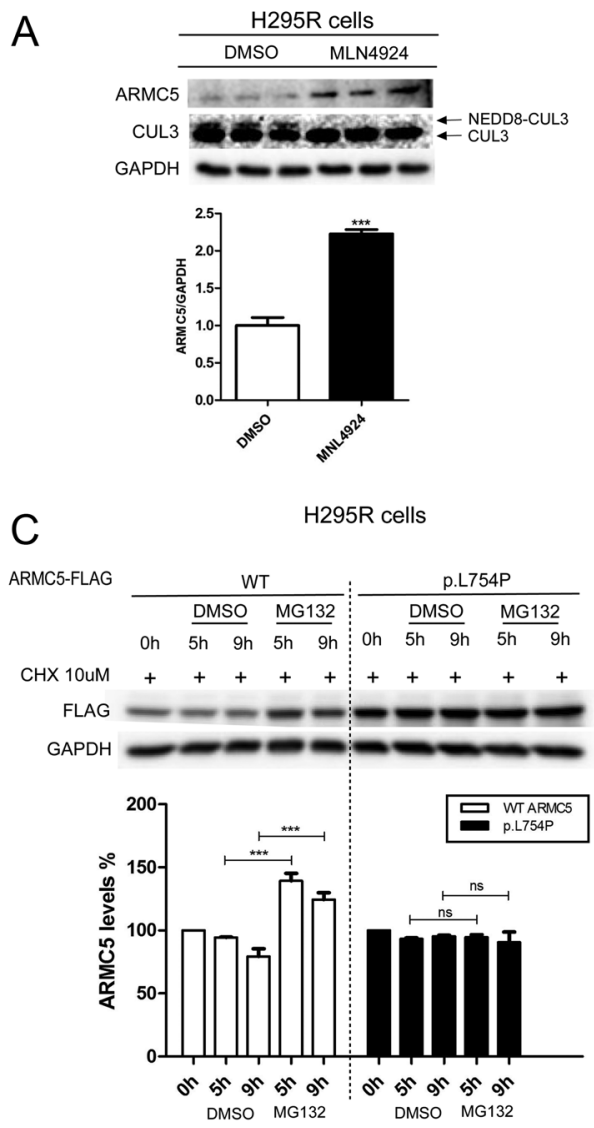

\section{ARMC5/CUL3 participates in the G1-S cell cycle progression}

We investigated cell cycle progression in cells depleted for ARMC5 compared to control cells. Propidium iodide DNA staining analyzed by flow cytometry in asynchronized cells showed that ARMC5 silencing decreases the percentage of cells in G1 phase and increases the percentage of cells in S phase in H295R and HEK293 cells (Fig. 5A and Supplementary Fig. 1A). Consistent with this cell cycle alteration, cyclin E mRNA and protein accumulation (essential for the cell cycle G1-S phase progression) were increased in ARMC5-deficient cells compared to control cells (Fig. 5B and Supplementary Figs 1B, 2). Moreover, ARMC5-deficient cells synchronized in late G1 phase with aphidicolin for $24 \mathrm{~h}$ and then released, progress in cell cycle faster than control cells (Supplementary Fig. 3A, B, $\mathrm{C}, \mathrm{D}, \mathrm{E}$ and $\mathrm{F}$ ). Indeed, $12 \mathrm{~h}$ after release, ARMC5-depleted cells returned to $\mathrm{G} 1$ phase more rapidly compared to control cells (Supplementary Fig. 3E). On the other hand, WT ARMC5 overexpression increased the percentage of cells in G1 phase (Fig. 5C and Supplementary Fig. 1C) and decreased cyclin E protein accumulation (Fig. 5D), suggesting a cell cycle arrest in G1 phase. These latest

\section{Figure 3}

ARMC5 is regulated by the ubiquitin/proteasome system in vitro. (A) Endogenous ARMC5 is stabilized by inhibition of cullin neddylation (NEDD8) with $2 \mu \mathrm{M}$ MLN4924 and (B) by proteasome inhibition with $20 \mu \mathrm{M}$ MG132 in H295R cells. (C) WT ARMC5 is less stable than the L754P ARMC5 mutant. The degradation of WT ARMC5 is blocked by proteasomal inhibition with $20 \mu \mathrm{M}$ MG132 during $4 \mathrm{~h}$, while no effect is observed in the L754P ARMC5 mutated protein. (D) Endogenous WT ARMC5 is stabilized by proteasomal inhibition with $20 \mu \mathrm{M}$ MG132 during $4 \mathrm{~h}$, while no effect is observed in H808P ARMC5 mutated protein in PBMAH cell cultures. Images are representative of at least three independent experiments. Significance was assessed by student's $t$-test for experiments shown in A and B, while two-way ANOVA followed by Bonferroni post-test was used for experiments shown in $C$ and $D$.

effects were not observed in cells which co-overexpressed CUL3 with ARMC5 (Fig. 5C, D and Supplementary Fig. 1C), suggesting that ubiquitination of ARMC5 by CUL3 alters its functions. As expected, ARMC5 p.L754P mutant overexpression (alone or in combination with CUL3) had no effect on the cell cycle phases or the accumulation of cyclin E protein (Fig. 5C, D and Supplementary Fig. 1C). These results show that ARMC5 is involved in cell cycle progression and the cyclin E accumulation. Moreover, this ARMC5 feature can be controlled by the CUL3/ proteasome system.

\section{Discussion}

Our results demonstrate that ARMC5 is a direct substrate of the CUL3 ubiquitin complex and that the BTB domain of ARMC5 is important for this interaction. ARMC5 degradation is prevented by mutations in its BTB domain or by CUL3 silencing/inhibition leading to increased ARMC5 half-life. Hence, ARMC5 stability is mainly regulated by CUL3, even though other mechanisms may be involved. Moreover, ARMC5 is involved in cell cycle progression (G1/S phases and cyclin E accumulation) and

(c) 2020 Society for Endocrinology Published by Bioscientifica Ltd. Printed in Great Britain 

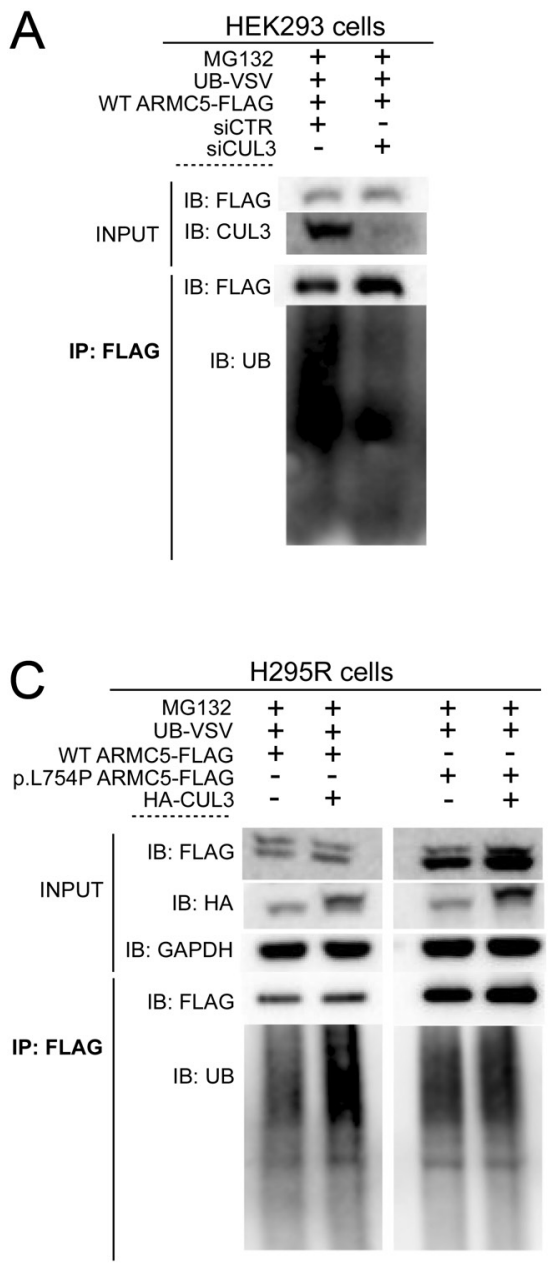
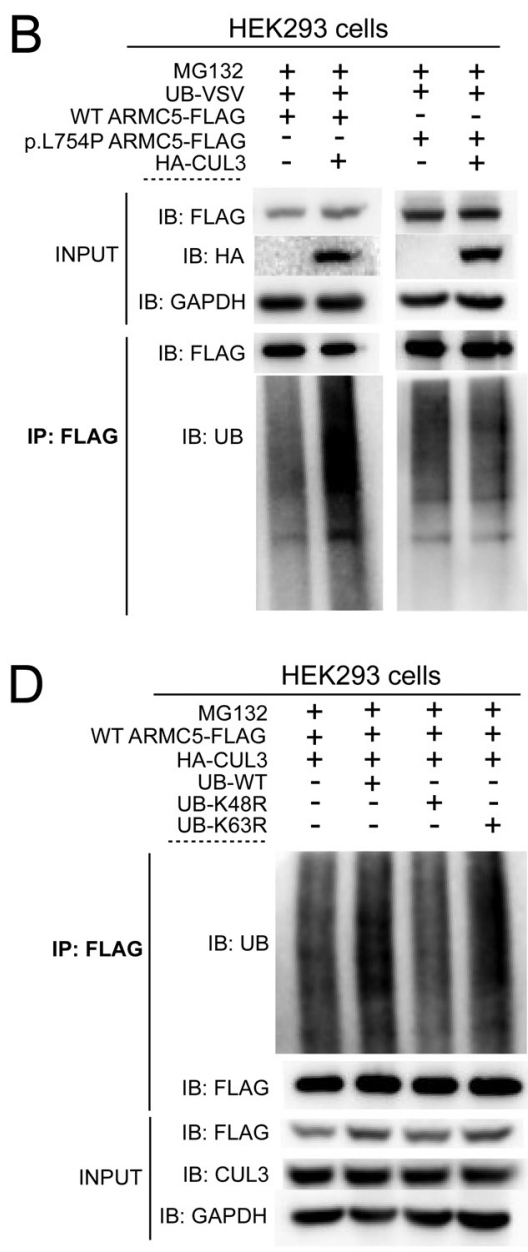

\section{Figure 4}

ARMC5 turnover is regulated by the CUL3-based ubiquitin complex. HEK293 cells were transfected with UB-WT, UB-K48R, UB-K63R, WT ARMC5-FLAG and HA-CUL3 as indicated in each experiment, followed by cell-based ubiquitination assays. (A) Followed by endogenous CUL3 knockdown, ubiquitination assays were performed. WT ARMC5 ubiquitination level was decreased in the absence of CUL3. Ubiquitination of WT ARMC5 was increased by the co-expression of HA-CUL3, while no effect was observed in the L754P mutant protein in HEK293 and H295R (B and C, respectively) cells. (D) Ubiquitination of WT ARMC5 was decreased by a mutation in the K48 ubiquitin chains, responsible for proteasome degradation, while no effect was observed by K63 ubiquitin mutated chains. Images are representative of at least three independent experiments. this effect is regulated by the CUL3/proteasome system. Interestingly, cyclin $\mathrm{E}$ was found to be overexpressed in other types of adrenocortical tumors (Bourcigaux et al. 2000, Tissier et al. 2004), suggesting a general role in adrenocortical pathophysiology. ARMC5 might not be just a target of CUL3 ubiquitin complex but also an adaptor protein for recruiting specific substrates. ARMC5 alterations would lead to an increase of one or more proteins acting as oncogenes. Indeed, several E3 ligases or adaptor proteins can be targeted for degradation in a self-ubiquitination manner (Wilkins et al. 2004, Zhou et al. 2015). Moreover, it has been suggested that the CUL3 dimer complex formation is mediated via the BTB domains of the substrate adaptors. In this way, a Yeast Two Hybrid assay in which ARMC5 protein served as bait identified ARMC5 as prey, suggesting a ARMC5 self-dimerization ( $\mathrm{Hu}$ et al. 2017). In this context, some ARMC5 missense mutants (as p.L754P) fail to bind CUL3 and would therefore not recruit target protein(s) for ubiquitination/degradation. Other ARMC5 missense mutants (as p.L548P and p.R898W), which are still able to bind CUL3, would not be able to recruit substrate(s) or to lead to their ubiquitination. As depletion of ARMC5 increases cyclin E accumulation and free full length cyclin $\mathrm{E}$ is known to be targeted by CRL3 complex (Lu \& Pfeffer 2013), we could speculate that ARMC5 could be an adaptor of the CUL3 complex leading to ubiquitination of cyclin E. However, ARMC5 silencing leads to increased CCNE1 mRNA accumulation (Supplementary Fig. 2), according to previously described PBMAH cell cultures (Cavalcante et al. 2018). Moreover, ARMC5 regulates preferentially low molecular cyclin E protein (Fig. 5B, D and Supplementary Fig. 1B), which have been shown to not be ubiquitinated by CUL3 (Singer et al. 1999, Davidge et al. 2019). These data suggest that ARMC5 regulates cyclin E by underlying mechanisms that remain to be elucidated. In this study, we show a novel mechanism of ARMC5 protein regulation, opening up new perspectives for the study of adrenal tumors. Consistent with this finding, recent studies highlight the growing evidences of the ubiquitination/proteasome system alterations in endocrine and more specifically adrenal and pituitary 

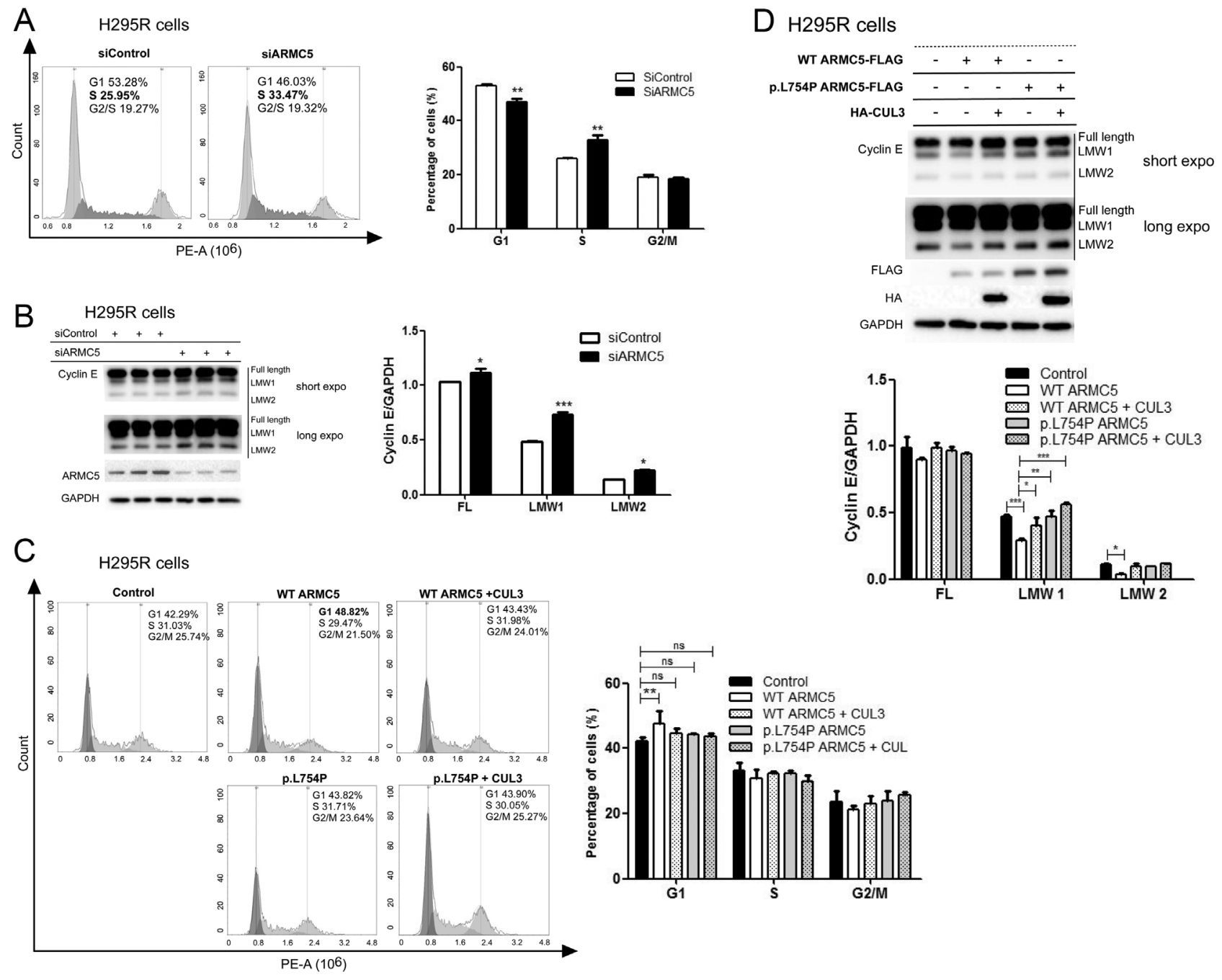

\section{Figure 5}

ARMC5 regulates cell cycle and cyclin E turnover in H295R cells. Propidium iodide was used to determine DNA content. (A) Flow cytometry analysis after ARMC5 depletion revealed a decrease in the percentage of cells in G1 phase and an increase in S phase. (B) Depletion of ARMC5 led to an increase in full length (FL) and low molecular weight (LMW) in cyclin E. (C) Overexpression of WT ARMC5 increases the number of cells in G1 phase and (D) inhibits cyclin E protein accumulation compared to control cells. However, co-expression of WT ARMC5 and CUL3 as well as overexpression of p.L754P mutated ARMC5 have no longer an effect in cell cycle and (D) in cyclin E inhibition. Images are representative of at least three independent experiments. Significance was assessed by using two-way ANOVA, followed by Bonferroni post-test.

tumors causing Cushing syndrome development. While the ubiquitin-specific protease 8 (USP8) gene is frequently altered in pituitary corticotroph adenomas (Ma et al. 2015, Reincke et al. 2015), the ubiquitin ligase SIAH1 is involved in the adrenal cortex organization (Scortegagna et al. 2017). Furthermore, the most frequently altered gene in aggressive adrenal tumors is an E3 ubiquitin ligase, ZNRF3 (Zinc and ring finger protein 3) (Assie et al. 2014, Zheng et al. 2016). Beyond being a substrate of the CUL3-based ubiquitin complex, we cannot exclude that ARMC5 might also be a substrate adaptor protein that recruits specific substrates for degradation. If confirmed, this mechanism could participate to the tumor suppressor function of
ARMC5. Further investigations are needed to identify other ARMC5 binding proteins and potential substrates for the CUL3-ARMC5 complex, ultimately leading to the identification of pathways regulated by ARMC5.

Supplementary materials

This is linked to the online version of the paper at https://doi.org/10.1530/ ERC-19-0502.

\section{Declaration of interest}

The authors declare that there is no conflict of interest that could be perceived as prejudicing the impartiality of the research reported. (c) 2020 Society for Endocrinology Published by Bioscientifica Ltd. Printed in Great Britain 


\section{Funding}

M C B V F and J B were supported in part by FAPESP-ANR (number 2015/50192-9), by the Fondation pour la Recherche Médicale (FRM) grant (EQU201903007864), by the ANR grant 18-CE14-008-01 and by Coordenação de Aperfeiçoamento de Pessoal de Nível Superior (CAPES). I P $C$ is a recipient of a post-doctoral fellowship of the FRM (SPF201809007096).

\section{Author contribution statement}

A Vaczlavik and L Drougat contributed equally to this work.

\section{References}

Alencar GA, Lerario AM, Nishi MY, Mariani BM, Almeida MQ, Tremblay J, Hamet P, Bourdeau I, Zerbini MC, Pereira MA, et al. 2014 ARMC5 mutations are a frequent cause of primary macronodular adrenal hyperplasia. Journal of Clinical Endocrinology and Metabolism 99 E1501-E1509. (https://doi.org/10.1210/jc.2013-4237)

Assie G, Libe R, Espiard S, Rizk-Rabin M, Guimier A, Luscap W, Barreau O, Lefevre L, Sibony M, Guignat L, et al. 2013 ARMC5 mutations in macronodular adrenal hyperplasia with Cushing's syndrome. New England Journal of Medicine 369 2105-2114. (https:// doi.org/10.1056/NEJMoa1304603)

Assie G, Letouze E, Fassnacht M, Jouinot A, Luscap W, Barreau O, Omeiri H, Rodriguez S, Perlemoine K, Rene-Corail F, et al. 2014 Integrated genomic characterization of adrenocortical carcinoma. Nature Genetics 46 607-612. (https://doi.org/10.1038/ng.2953)

Bennett EJ, Rush J, Gygi SP \& Harper JW 2010 Dynamics of cullin-RING ubiquitin ligase network revealed by systematic quantitative proteomics. Cell 143 951-965. (https://doi.org/10.1016/j. cell.2010.11.017)

Berthon A, Faucz F, Bertherat J \& Stratakis CA 2017a Analysis of ARMC5 expression in human tissues. Molecular and Cellular Endocrinology $\mathbf{4 4 1}$ 140-145. (https://doi.org/10.1016/j.mce.2016.08.018)

Berthon A, Faucz FR, Espiard S, Drougat L, Bertherat J \& Stratakis CA $2017 b$ Age-dependent effects of Armc5 haploinsufficiency on adrenocortical function. Human Molecular Genetics 26 3495-3507. (https://doi.org/10.1093/hmg/ddx235)

Bourcigaux N, Gaston V, Logie A, Bertagna X, Le Bouc Y \& Gicquel C 2000 High expression of cyclin E and G1 CDK and loss of function of p57KIP2 are involved in proliferation of malignant sporadic adrenocortical tumors. Journal of Clinical Endocrinology and Metabolism 85 322-330. (https://doi.org/10.1210/jcem.85.1.6303)

Bourdeau I, Oble S, Magne F, Levesque I, Caceres KY, Nolet S, Awadalla P, Tremblay J, Hamet P, Fragoso MC, et al. 2016 ARMC5 mutations in a large French-Canadian family with cortisol-secreting beta-adrenergic/vasopressin responsive bilateral macronodular adrenal hyperplasia. European Journal of Endocrinology 174 85-96. (https://doi.org/10.1530/EJE-15-0642)

Cavalcante IP, Nishi M, Zerbini MCN, Almeida MQ, Brondani VB, Botelho MLAA, Tanno FY, Srougi V, Chambo JL, Mendonca BB, et al. 2018 The role of ARMC5 in human cell cultures from nodules of primary macronodular adrenocortical hyperplasia (PMAH). Molecular and Cellular Endocrinology 460 36-46. (https://doi.org/10.1016/j. mce.2017.06.027)

Ciechanover A 2017 Intracellular protein degradation: from a vague idea thru the lysosome and the ubiquitin-proteasome system and onto human diseases and drug targeting. Best Practice and Research: Clinical Haematology 30 341-355. (https://doi.org/10.1016/j.beha.2017.09.001)

Davidge B, Rebola KGO, Agbor LN, Sigmund CD \& Singer JD 2019 Cul3 regulates cyclin E1 protein abundance via a degron located within the N-terminal region of cyclin E. Journal of Cell Science $\mathbf{1 3 2}$ jcs.233049. (https://doi.org/10.1242/jcs.233049)

Dubiel W, Dubiel D, Wolf DA \& Naumann M 2018 Cullin 3-based ubiquitin ligases as master regulators of mammalian cell differentiation. Trends in Biochemical Sciences 43 95-107. (https://doi. org/10.1016/j.tibs.2017.11.010)

Elbelt U, Trovato A, Kloth M, Gentz E, Finke R, Spranger J, Galas D, Weber S, Wolf C, Konig K, et al. 2015 Molecular and clinical evidence for an ARMC5 tumor syndrome: concurrent inactivating germline and somatic mutations are associated with both primary macronodular adrenal hyperplasia and meningioma. Journal of Clinical Endocrinology and Metabolism 100 E119-E128. (https://doi. org/10.1210/jc.2014-2648)

Espiard S, Drougat L, Libe R, Assie G, Perlemoine K, Guignat L, Barrande G, Brucker-Davis F, Doullay F, Lopez S, et al. 2015 ARMC5 mutations in a large cohort of primary macronodular adrenal hyperplasia: clinical and functional consequences. Journal of Clinical Endocrinology and Metabolism 100 E926-E935. (https://doi. org/10.1210/jc.2014-4204)

Faucz FR, Zilbermint M, Lodish MB, Szarek E, Trivellin G, Sinaii N, Berthon A, Libe R, Assie G, Espiard S, et al. 2014 Macronodular adrenal hyperplasia due to mutations in an armadillo repeat containing 5 (ARMC5) gene: a clinical and genetic investigation. Journal of Clinical Endocrinology and Metabolism 99 E1113-E1119. (https://doi.org/10.1210/jc.2013-4280)

Gagliardi L, Schreiber AW, Hahn CN, Feng J, Cranston T, Boon H, Hotu C, Oftedal BE, Cutfield R, Adelson DL, et al. 2014 ARMC5 mutations are common in familial bilateral macronodular adrenal hyperplasia. Journal of Clinical Endocrinology and Metabolism 99 E1784-E1792. (https://doi.org/10.1210/jc.2014-1265)

Hu Y, Lao L, Mao J, Jin W, Luo H, Charpentier T, Qi S, Peng J, Hu B, Marcinkiewicz MM, et al. 2017 Armc5 deletion causes developmental defects and compromises T-cell immune responses. Nature Communications 8 13834. (https://doi.org/10.1038/ncomms13834)

Huttlin EL, Bruckner RJ, Paulo JA, Cannon JR, Ting L, Baltier K, Colby G, Gebreab F, Gygi MP, Parzen H, et al. 2017 Architecture of the human interactome defines protein communities and disease networks. Nature 545 505-509. (https://doi.org/10.1038/ nature22366)

Lu A \& Pfeffer SR 2013 Golgi-associated RhoBTB3 targets cyclin E for ubiquitylation and promotes cell cycle progression. Journal of Cell Biology 203 233-250. (https://doi.org/10.1083/jcb.201305158)

Ma ZY, Song ZJ, Chen JH, Wang YF, Li SQ, Zhou LF, Mao Y, Li YM, Hu RG, Zhang ZY, et al. 2015 Recurrent gain-of-function USP8 mutations in Cushing's disease. Cell Research 25 306-317. (https:// doi.org/10.1038/cr.2015.20)

Morreale FE \& Walden H 2016 Types of ubiquitin ligases. Cell 165248 248.e1. (https://doi.org/10.1016/j.cell.2016.03.003)

Ragazzon B, Cazabat L, Rizk-Rabin M, Assie G, Groussin L, Fierrard H, Perlemoine K, Martinez A \& Bertherat J 2009 Inactivation of the Carney complex gene 1 (protein kinase A regulatory subunit 1A) inhibits SMAD3 expression and TGF beta-stimulated apoptosis in adrenocortical cells. Cancer Research 69 7278-7284. (https://doi. org/10.1158/0008-5472.CAN-09-1601)

Reincke M, Sbiera S, Hayakawa A, Theodoropoulou M, Osswald A, Beuschlein F, Meitinger T, Mizuno-Yamasaki E, Kawaguchi K, Saeki Y, et al. 2015 Mutations in the deubiquitinase gene USP8 cause Cushing's disease. Nature Genetics 47 31-38. (https://doi.org/10.1038/ ng.3166)

Scortegagna M, Berthon A, Settas N, Giannakou A, Garcia G, Li JL, James B, Liddington RC, Vilches-Moure JG, Stratakis CA, et al. 2017 The E3 ubiquitin ligase Siah1 regulates adrenal gland organization and aldosterone secretion. JCI Insight 2 97128. (https://doi. org/10.1172/jci.insight.97128)

Singer JD, Gurian-West M, Clurman B \& Roberts JM 1999 Cullin-3 targets cyclin $\mathrm{E}$ for ubiquitination and controls $\mathrm{S}$ phase in (c) 2020 Society for Endocrinology Published by Bioscientifica Ltd. Printed in Great Britain 
mammalian cells. Genes and Development 13 2375-2387. (https://doi. org/10.1101/gad.13.18.2375)

Tissier F, Louvel A, Grabar S, Hagnere AM, Bertherat J, VacherLavenu MC, Dousset B, Chapuis Y, Bertagna X \& Gicquel C 2004 Cyclin E correlates with malignancy and adverse prognosis in adrenocortical tumors. European Journal of Endocrinology 150 809-817. (https://doi.org/10.1530/eje.0.1500809)

Wilkins A, Ping Q \& Carpenter CL 2004 RhoBTB2 is a substrate of the mammalian Cul3 ubiquitin ligase complex. Genes and Development 18 856-861. (https://doi.org/10.1101/gad.1177904)

Zhang DD, Lo SC, Cross JV, Templeton DJ \& Hannink M 2004 Keap1 is a redox-regulated substrate adaptor protein for a Cul3-dependent ubiquitin ligase complex. Molecular and Cellular Biology 24 10941-10953. (https://doi.org/10.1128/MCB.24.24.1094110953.2004)

Zheng S, Cherniack AD, Dewal N, Moffitt RA, Danilova L, Murray BA, Lerario AM, Else T, Knijnenburg TA, Ciriello G, et al. 2016 Comprehensive pan-genomic characterization of adrenocortical carcinoma. Cancer Cell 30 363. (https://doi.org/10.1016/j. ccell.2016.07.013)

Zhou Z, Xu C, Chen P, Liu C, Pang S, Yao X \& Zhang Q 2015 Stability of HIB-Cul3 E3 ligase adaptor HIB is regulated by self-degradation and availability of its substrates. Scientific Reports 5 12709. (https:// doi.org/10.1038/srep12709)

Received in final form 29 January 2020

Accepted 5 February 2020

Accepted Manuscript published online 5 February 2020
(C) 2020 Society for Endocrinology Published by Bioscientifica Ltd. Printed in Great Britain 